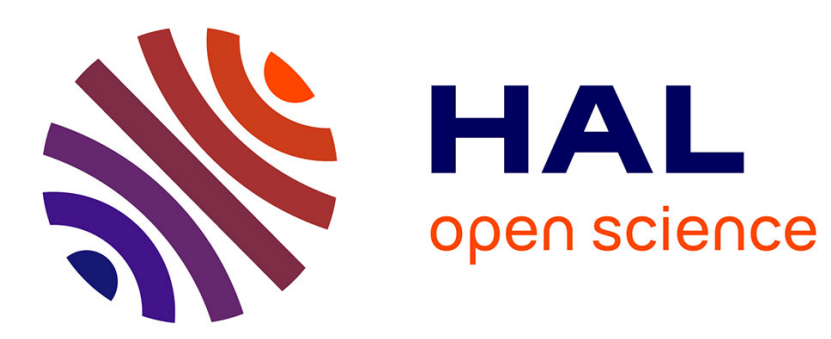

\title{
Site distribution and thermalization effects in europium-doped silica glasses
}

\author{
Adel Bouajaj, A. Monteil, C. Bovier, M. Ferrari, A. Piazza
}

\section{To cite this version:}

Adel Bouajaj, A. Monteil, C. Bovier, M. Ferrari, A. Piazza. Site distribution and thermalization effects in europium-doped silica glasses. Journal de Physique IV Proceedings, 1994, 04 (C4), pp.C4579-C4-582. 10.1051/jp4:19944139 . jpa-00252591

\section{HAL Id: jpa-00252591 https://hal.science/jpa-00252591}

Submitted on 1 Jan 1994

HAL is a multi-disciplinary open access archive for the deposit and dissemination of scientific research documents, whether they are published or not. The documents may come from teaching and research institutions in France or abroad, or from public or private research centers.
L'archive ouverte pluridisciplinaire HAL, est destinée au dépôt et à la diffusion de documents scientifiques de niveau recherche, publiés ou non, émanant des établissements d'enseignement et de recherche français ou étrangers, des laboratoires publics ou privés. 


\title{
Site distribution and thermalization effects in europium-doped silica glasses
}

\author{
A. BOUAJAJ, A. MONTEIL ${ }^{*}$, C. BOVIER ${ }^{* *}$, M. FERRARI $^{* * *}$ and A. PIAZZA ${ }^{* * * *}$
}

Physico-Chimie des Matériaux Luminescents, URA 442 du CNRS, Université Lyon I, 43 bd du 11 Novembre 1918, 69622 Villeurbanne, France

* Laboratoire POMA, Université d'Angers, 2 bd Lavoisier, 49045 Angers cedex, France

${ }^{* *}$ Département de Physique des Matériaux, URA 172 du CNRS, Université Lyon I, 43 bd du 11 Novembre 1918, 69622 Villeurbanne, France

${ }^{* * *}$ CNR, Centro di Fisica degli Stati Aggregati ed Impianto Ionico, via Sommarive 14, 38050 Povo (TN), Italy

\begin{abstract}
For the no-phonon transition ${ }^{5} \mathrm{D}_{0} \rightarrow{ }^{7} \mathrm{~F}_{0}$ of $\mathrm{Eu}^{3+}$ in glasses, obtained by sol-gel route, emission and absorption at low temperature are not resonant. This effect is interpreted by a redistribution of the excitation energy among the different environment for the $\mathrm{Eu}^{3+}$ ion. A simple model is used to interpret the temperature evolution of the emission spectra. A good agreement is obtained with experimental results. The experimental emission spectra are simulated using the Boltzmann law and the experimental excitation spectra. The mechanism of redistribution is a phonon-assisted energy transfer process. This is confirmed by temperature dependance of decays and time resolved emission measurements.
\end{abstract}

\section{Introduction}

Because the particular relevance of sol-gel optical materials it is important to control their final properties. For this purpose it is necessary to understand the modifications induced by the densification process [1]. A powerful method to study the local structure and the dynamical processes involved in such systems, is to use the spectroscopical properties of optically active ions. Several works have been devoted to study the densification process of sol-gel with rare-earth ions as probe [2]. $\mathrm{Eu}^{3+}$ has been widely used both in crystalline and glassy materials because its optical transitions are very sensitive to the local surroundings and one of its transition: ${ }^{5} \mathrm{D}_{0} \leftrightarrow{ }^{7} \mathrm{~F}_{0}$ is a singlet. In this work we follow the evolution of this line at different stages of the densification process of acidcatalyzed gels. For sample heated above $500^{\circ} \mathrm{C}$ we have found that emission and absorption are not resonant contrary to what it is expected for a no-phonon transition. Finally a model that explains this effect is presented.

\section{Experimental}

Gels were prepared by hydrolysis and condensation of tetramethylorthosilicate (TMOS), methanol and water with the following molar ratios: TMOS/MeOH $/ \mathrm{H}_{2} \mathrm{O}=$ 1/6.2/10. An acidic aqueous solution of $\mathrm{Eu}\left(\mathrm{NO}_{3}\right)_{3}$ was then added in order to reach the desired $\mathrm{Eu}^{3+}$ concentration: $\mathrm{Eu} / \mathrm{Si}=0.002$. Starting from a wet gel (a) several samples were successively heated $10 \mathrm{~h}$ to 
$200{ }^{\circ} \mathrm{C}$ (b) $500{ }^{\circ} \mathrm{C}$ (c) $800{ }^{\circ} \mathrm{C}$ (d) and $1050^{\circ} \mathrm{C}$ (e) with a rate of 0.1 ${ }^{\circ} \mathrm{C} / \mathrm{mn}$.

Excitation spectra were obtained using a Rh6G dye laser pumped by excimer laser. A xenon lamp coupled with a monochromator was used for broadband excitation. The fluorescence was focused onto a model 1401 double Spex monochromator equipped with a cooled RCA C31034A02 photomultiplier tube. The average resolution in the region of interest was $0.3 \mathrm{~cm}^{-1}$.

\section{Results and Discussion}

Figure 1 shows the low temperature excitation spectra of the ${ }^{5} \mathrm{D}_{0} \leftarrow{ }^{7} \mathrm{~F}_{0}$ transition for different heat treated samples. In this condition the whole inhomogeneous site distribution is detected. The Full Width Half Maximum (FWHM) of the line varies from $17 \mathrm{~cm}^{-1}$ for the wet gel (Fig. 1a) up to $155 \mathrm{~cm}^{-1}$ for the sample heated to $800{ }^{\circ} \mathrm{C}$ (Fig. 1d). This evolution comes from the effect of the expulsion of solvent and from the polycondensation of the silica chains. The system goes from a liquid-like environment towards a dry and densified environment [3]. For the fully densified we observe a narrower linewidth of $115 \mathrm{~cm}^{-1}$ (Fig. 1e) that reflects a rearrangement of the silica network. For the sample heated to 200 ${ }^{\circ} \mathrm{C}$ (Fig. 1b) two peaks are observed at $17247 \mathrm{~cm}^{-1}$ and $17267 \mathrm{~cm}^{-1}$. The first one is related to the liquid-like environment, as for the peak of Fig. 1a, and the second one is related to the dry environment [4].

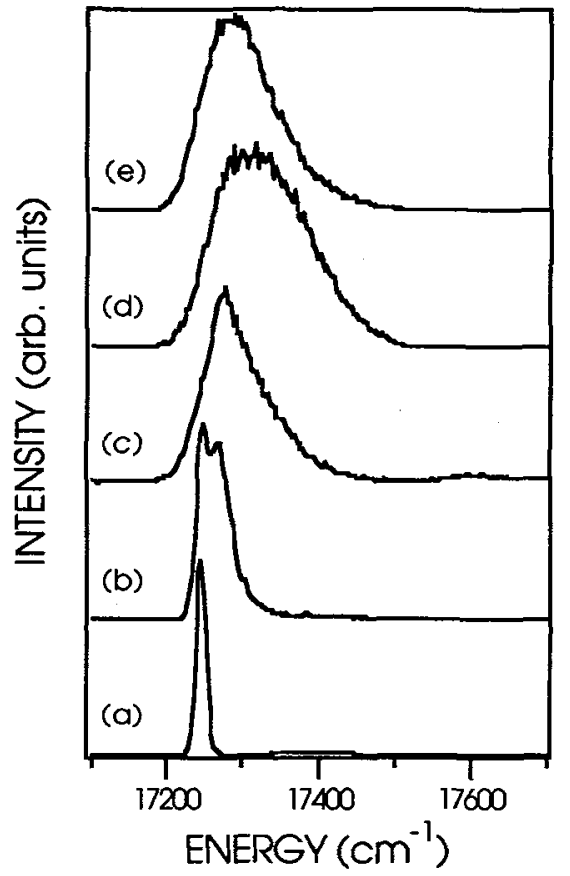

Fig. 1: ${ }^{5} D_{0} \leftarrow{ }^{7} F_{0}$ excitation spectra at $10 \mathrm{~K}$ for different heat treatments.

Figure 2 shows the low temperature emission spectra for the ${ }^{5} \mathrm{D}_{0} \rightarrow{ }^{7} \mathrm{~F}_{0}$ transition. The main feature consists in a displacement of the barycenter towards the lower energies, from $17245 \mathrm{~cm}^{-1}$ for the wet gel (Fig. 2a) to $17212 \mathrm{~cm}^{-1}$ for the fully densified sample (Fig 2e). The positive shift of few wavenumbers observed for the gel treated to $200{ }^{\circ} \mathrm{C}$ (Fig. 2b) is due to an increase of the number of "dry" sites as observed in the excitation spectra. In heated samples we can remark that the linewidth is narrower for emission spectra than for excitation spectra. For instance we get a FWHM of $55 \mathrm{~cm}^{-1}$ for the sample heated to $800^{\circ} \mathrm{C}$ (Fig. 2d). 


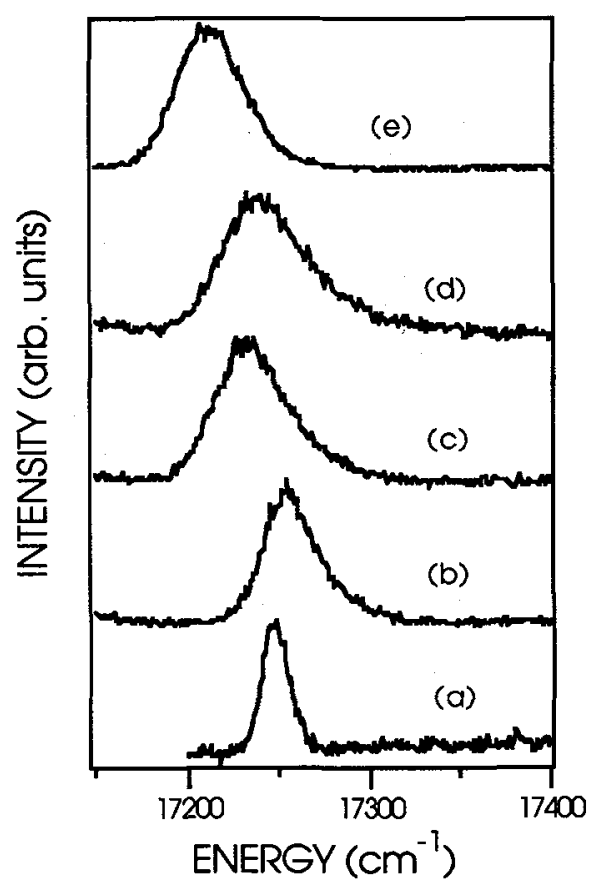

Fig. 2: ${ }^{5} D_{0} \rightarrow{ }^{7} F_{0}$ emission spectra at $10 \mathrm{~K}$ for different heat treatments. Excitation with a Xenon lamp at $395 \mathrm{~nm}$.

This value has to be compared with the $155 \mathrm{~cm}^{-1}$ observed in the excitation spectrum. Since the transition is a no-phonon line, it is expected that both emission and absorption or excitation lines are identical. The observed differences must be interpreted considering the inhomogeneous nature of the line. In fact the ${ }^{5} D_{0}$ energy level varies from site to site due to the different strengths of the local crystal field around the europium ions. The excitation is redistributed between the ions by a phonon-assisted energy transfer. The relative population of the ${ }^{5} D_{0}$ states follows a Boltzmann thermodynamic law. In fact at room temperature emission and excitation spectra are well superimposed. This thermal dependance is confirmed by a simple model that we have applied to the fully densified sample. We have calculated the emission spectra $f_{\mathrm{em}}(E)$ at different temperatures as:

$$
f_{\mathrm{em}}(E, T)=f_{\mathrm{ex}}(E) \times \exp -\left[\frac{\left(E-E_{0}\right)}{k T}\right]
$$

where $f_{\text {ex }}$ is the experimental excitation spectrum recorded at $\mathrm{T}=10$ $\mathrm{K}$ shown in Fig. 1e, $\mathrm{E}_{0}$ is the lowest energy in the inhomogeneous distribution of the ${ }^{5} \mathrm{D}_{0}$ states taken at $17192 \mathrm{~cm}^{-1}$ as obtained in the excitation spectra $f_{\mathrm{ex}}$.

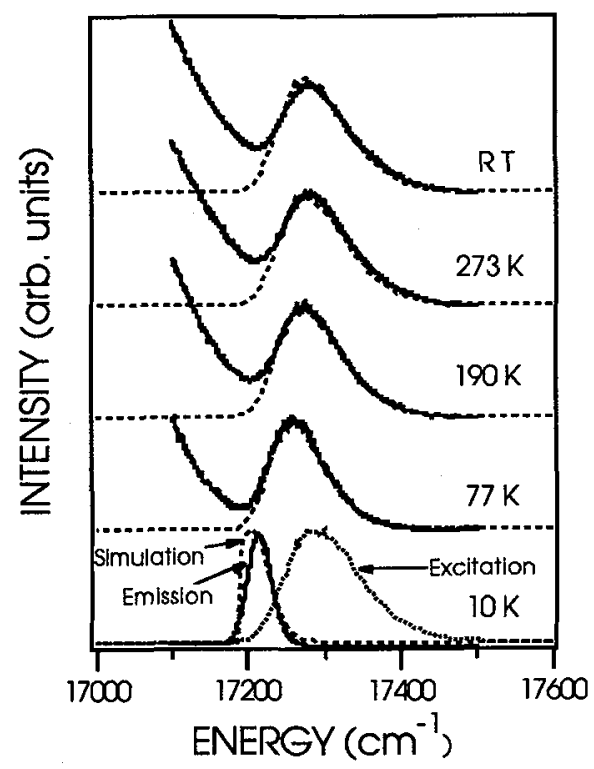

Fig. 3: ${ }^{5} \mathrm{DO}_{\mathrm{O}} \rightarrow{ }^{7} \mathrm{~F}_{\mathrm{O}}$ experimental and simulated emission spectra at different temperatures for the full densified sample e.

Simulated spectra with experimental emission spectra are shown on Fig. 3 for different tem- 
peratures. Simulated spectra are in good agreement with experimental ones.

Preliminary measurements in time resolved Fluorescence Line Narrowing experiments show that energy transfer between different sites is active. Its efficiency increases with the densification of the sample. In fact it becomes more important thanks to the vibrational modes of the silica network involved in the process. Moreover it is inferred from the temperature dependance that the process is mainly phonon-assisted. Demonstration and analysis of the energy transfer process present in this system will be the subject of a future paper [5].

\section{Acknowledgements}

We wish to thank Professor E. Duval and Professor M. Montagna for helpful discussions.

\section{References}

[1] see e.g. L. C. Klein, Annu. Rev. Mater. Sci. 23, 437 (1993) R. Reisfeld and C. K. Jørgensen, Structure and Bonding 77, 207 (1992)

[2] D. Levy, R. Reisfeld, D. Avnir, Chem. Phys. Lett., 109, 593 (1984) K. Devlin, B. O'Kelly, Z. R. Tang, C. McDonagh, J. F. McGilp, J. NonCryst. Solids 135, 8 (1991)

[3] R.Campostrini, G. Carturan, M. Ferrari, M. Montagna, O. Pilla J. of Material Research.7, 745, (1992)

[4] A.Piazza, A.Bouajaj, M.Ferrari, M. Montagna, R.Campostrini, G. Carturan. Laser M2P Lyon December 1993.

[5] A. Bouajaj, A. Monteil, E. Duval, M. Ferrari and M. Montagna to be published. 